\title{
The unending pursuit
}

\author{
Richard Smith
}

Quality is a word in danger of devaluation. It might become a word like "love, happiness, or freedom," something that people are willing to die for but are unable to define or measure. Alternatively, it might become what Philip Howard calls a weasel word - a word with the meaning sucked from it in the way that a weasel sucks the contents from eggs, leaving only the shell. ${ }^{1}$ Indeed, quality did appear in Howard's list of weasel words published in 1980. He observed about the word: "noun used as adjective, as in 'quality press'; in the commercial world nothing is ever of bad quality."

So when we talk of raising quality in the NHS or in a health care system we must be as clear as we can about what we are trying to achieve. We must do more than simply call for more quality as we might call for more virtue or happiness, and we must avoid attaching the word quality to every small innovation. We should reserve the word to signify our constant pursuit of better ways of satisfying our patients' needs.

Because although quality will never be reached and can never be exactly defined, we can recognise its absence without difficulty. As I write, "we have the builders in," and building work in Britain - despite Durham cathedral and the Queen's House, Greenwich - is often associated with poor quality. These builders not only use poor materials and do things that are functionally and aesthetically flawed but they also never keep appointments or promises, never offer explanations of why things have gone wrong, never apologise, and never even seem to understand why we are upset. They offer a service that seems to me utterly devoid of quality, and I find myself wondering if any patient in the NHS has ever had such a miserable experience. Sadly, I think that I could find such patients.

I think that everybody who attended the conference and who reads this supplement will agree that raising quality is something worth doing. None of us could put our hand on our heart and say that there isn't anything that we do that we couldn't do better. That is why "every defect is a treasure." If my builders decided that they wanted to raise the quality of their service then they would be awash with treasure. Their problem would be to decide what to improve first, but they would discover that a huge amount could be achieved simply by deciding that they want to do better. It might take them a long time to improve their construction skills and find their way to better materials, but tomorrow they could start keeping their appointments and promises - or at the very least they could offer believable explanations of why they are not.

\section{Recognising opportunities}

The first requirements for raising quality are thus to recognise that you have an opportunity to do better and to commit yourself to doing so. My builders if pressed would probably admit that they could provide a better service, but they have not recognised the full horror of the service they offer and certainly have not committed themselves to doing better. They are too busy getting on with the important tasks of finding jobs and completing them. They know that they have built houses, refurbished rooms, and damp proofed cellars. I think that many people in the health service may think in the same way: there are babies to be delivered, gall bladders to be removed, and cases of meningitis to be treated, and fretting about raising quality may get in the way of those important processes.

The next crucial requirement for raising quality is to create an environment in which fear is banished and people can confess that they have made mistakes. Even when they accidentally cut through a water pipe, my builders cannot admit that they have made a mistake. Those working in the NHS often have equal difficulty admitting to mistakes for fear of their bosses or of litigation. Yet the problem must be acknowledged for there to be any hope of improvement.

One of the central ideas of total quality management is that "there are no bad people only bad systems." If we accept this then we are much less likely to blame individuals for errors. (Making individuals scapegoats is usually the first and last resort of the managerially incompetent.) People who are doing their best within bad systems must feel able to draw attention to errors rather than hide them. Many of those working for my builders knew that things were going badly wrong but couldn't say so for fear of dismissal.

\section{Importance of systems}

The recognition of the importance of systems rather than individuals means also that all of us working in the NHS must work together to improve quality. We may feel nervous about letting others see what we don't do well, but health care - like most activities these days is very much a team effort. If hospital doctors try to improve the care of diabetic patients without including primary health care teams, nurses, dieticians, pharmacists, receptionists,
Journal, London WC1H 9JR

Richard Smith, editor 
those who keep the records, and managers then they are unlikely to make much progress because all of those people have a crucial part to play in the system that provides diabetic care. If my builders recognised their interdependence more and spent more time planning how they worked together then I would be much less unhappy than I am now. As it was, the carpenters didn't tell the plasterer what they were going to do and so work done had to be undone.

The pursuit of quality should lead those working in the NHS to recognise much more their interdependence. It should help to break down the longstanding tribal boundaries within the NHS and bring people closer together.

\section{Patients must define quality}

We must also recognise that patients must define quality. Many professionals find this hard to accept. They recognise the primacy of patients but think that patients cannot possibly understand enough about the processes of health care to know whether their blood glucose concentration is adequately controlled or their retinopathy well managed. But when we stop to think we realise that the only point in undertaking these technical measurements and processes is to make life better for patients. If the blood glucose concentration is better controlled but the patient feels worse then high quality has not been achieved. If my builders tell me that the joints in the stairs are outstandingly well made but I think that they have left insufficient head room then the job is poorly done - the quality is low.

Or consider the example of patients who demand antibiotics for their viral sore throats. If we allow those patients to define quality, say traditionalists, then we will be practising low quality medicine because we will be prescribing antibiotics, which carry a risk of adverse effects, for a condition in which they will produce no benefit. But if we don't prescribe the antibiotics we might feel that the service is good but the patients will think it is bad. The trick is to find a way to convince the patient that the antibiotics are unneccessary. This might mean educating patients, but it probably also means educating ourselves about why it is that the patients insist on antibiotics. What need is unsatisfied? By following this path we should end up with a service that is high quality: the antibiotics will not be prescribed but the patients will understand why and will have had their other needs met in better ways.

Once we do genuinely recognise that patients must define quality then we will be restoring patients to their central place in health care. Despite the lip service that everything is done for the benefit of patients, I often think that this is not truly the case. Too much of what is undertaken in hospital is actually undertaken for the convenience of doctors, nurses, and other staff - like, for instance, getting patients up at 6 am or giving men general anaesthetics before vasectomies.
The fact that patients must define quality puts communication at the heart of the effort to raise quality. If patients cannot understand what we are saying to them then the quality of a service can never be high no matter how excellent the surgery or how devoted the nurses. My builders are inclined to blind me with technicalities when I question them, and doctors tend to do the same. And it's terribly easy for doctors. They have at their command a vocabulary of unintelligible words that is the size of a small African language. But the failure to communciate arises not only from unintelligible words: doctors may use words that are understandable and still fail to communicate. Communciation is more about listening than talking, and doctors need to listen closely to what patients are saying hearing the subtext as well as the words - and then constantly check that their reply to the patients is being understood. Most important messages will also need to be repeated several times and presented in various forms, probably also in writing.

\section{Measuring performance}

Another important principle in the search for better quality must be that the pursuit is based on data and measurement. Without such measurements we are in danger of thinking that we are doing better than we are and deceiving ourselves that things are improving when they are not. Thus although the search for higher quality calls on us to re-examine cultural attitudes that are deep seated and in some sense "soft," it also requires us to be precise and deal scientifically with solid data.

All of these messages have profound implications for professional education. Just as we need to be helping students to learn how to learn so we need to be helping them to make constantly raising quality part of their professional life. Teachers need to be helping students to understand how to use data scientifically, how to think in terms of systems rather than individuals, and how to create and work in environments that allow people to be open about their weaknesses. Our present educational system is poor on data and system analysis and tends to encourage students to hide their ignorance.

Finally, as David Eddy has said, improving quality is not only a matter of doing the thing right but also doing the right thing. ${ }^{2}$ Much of what we do in health care has no scientific base and much of what we publish in medicine is scientifically unsound. ${ }^{3}$ The pursuit of quality will inevitably lead us to recognise this more, and again this thinking needs to be fed back into the education of those who work in the health care system.

In conclusion, the pursuit of quality in health care might seem to some like a passing fashion. The word quality is annoyingly imprecise, and some may think that the health care professionals should stick to trying to do as much as they can with inevitably limited resources rather than concerning themselves with pursuing a phantom. But the way that quality demands commitment, attitudinal 
changes, the collection of data, the 1 Howard P. Words fail me. London: Hamish Hamilton, reconsideration of much medical practice, and the placing of the patient at the centre of $31991 ; 303: 798-9$. 1980.
Smith $R$. Where is the wisdom . . . ? $B M \mathcal{F}$ everything means that it has the potential to (in press). 